\title{
Análise da Relação entre a Expressão da Proteína VEGF e o Estadiamento do Câncer Colorretal
}

\author{
Analysis of Relationship Between VEGF Protein Expression and Colorectal \\ Câncer Staging
}

\author{
LEANDRO MUTSCHALL ${ }^{1,2}$, PAULO CONDEIXA DE FRANÇA ${ }^{1}$, LESLIE ECKER FERREIRA ${ }^{1}$, \\ HERCILIO FRONZA JR. ${ }^{2}$, RODRIGO BLASIOS ${ }^{2}$, MAURO PINHO ${ }^{1,3}$
}

\section{Laboratório de Pesquisas Biomoleculares, UNIVILLE, Joinville, SC, Brasil; 2. Serviços Integrados de Patologia,} Joinville, SC, Brasil; 3. Departamento de Cirurgia, Hospital São José, Joinville, SC, Brasil.

\begin{abstract}
MUTSCHALL L; FRANÇA PC; FERREIRA LE; FRONZA JR H; BLASIOS R; PINHO M. Análise da Relação entre a Expressão da Proteína VEGF e o Estadiamento do Câncer Colorretal. Rev bras Coloproct, 2009;29(1): 015-0022.

RESUMO: Os estudos em biologia molecular desenvolvidos nas últimas décadas, possibilitaram grandes avanços para uma maior compreensão da carcinogênese colorretal. Na década de 80 pesquisadores descobriram uma proteína com a capacidade de aumentar a permeabilidade dos vasos sangüíneos. Inicialmente esta proteína foi denominada como fator de permeabilidade vascular. Estudos posteriores correlacionaram esta proteína com o crescimento de novos vasos sangüíneos (angiogênese), quando passou a ser chamada de fator de crescimento endotelial vascular (VEGF). A proteína VEGF tem sido apontada como o principal fator promotor da angiogênese, dentre os vários já conhecidos. Neste trabalho o objetivo foi quantificar a proteína VEGF, e correlacionar os resultados com o estadiamento tumoral em amostras de adenocarcinoma colorretal. Foram incluídos 56 adenocarcinomas colorretais, nos quais a detecção da proteína VEGF foi realizada por imunoistoquímica através da construção de uma matriz tecidual e sua quantificação com análise digital de imagens assistida por computador. Nossos resultados não evidenciaram relação estatisticamente significativa entre a expressão da proteína VEGF e o estadiamento tumoral, ou presença e número de linfonodos comprometidos. Baseado no nível de expressão da proteína VEGF não foi possível inferir a presença de linfonodos comprometidos nas amostras analisadas.
\end{abstract}

Descritores: Câncer colorretal; biologia molecular; VEGF; estadiamento; imunoistoquímica.

Os estudos em biologia molecular desenvolvidos ao longo das duas últimas décadas possibilitaram grandes avanços no sentido de uma maior compreensão da carcinogênese colorretal. Considerando a existência de estágios intermediários determinados pela presença de pólipos com diferentes graus neoplásicos, Fearon e Vogelstein realizaram trabalhos pioneiros ao analisar o processo de degeneração da mucosa colônica normal até o surgimento de um carcinoma em pacientes portadores de polipose adenomatosa familiar, demonstrando a ocorrência de um acúmulo de mutações em genes expressando proteínas com ação sobre as divisões celulares, como a APC, k-ras, DCC e p53 $3^{1,2}$.
Embora estes conceitos iniciais tenham sido de grande valor, tornou-se logo evidente sua excessiva simplicidade devido à demonstração de que estas proteínas representavam não apenas um número extremamente reduzido de genes/proteínas envolvidas no processo de carcinogênese, mas também contemplavam apenas um aspecto desta, representada pelo distúrbio proliferativo, etapa primordial, porém insuficiente para o surgimento da neoplasia invasiva.

Folkman (1971) propôs no princípio da década de setenta a importante participação do desenvolvimento de microcirculação no processo de crescimento tumoral. Denominado como angiogênese, este proces-

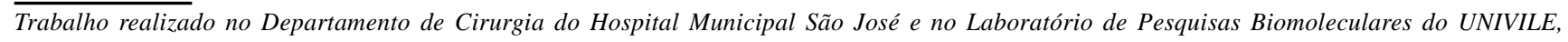
Joinvile, SC, Brasil. 
Análise da Relação entre a Expressão da Proteína VEGF

e o Estadiamento do Câncer Colorretal

Leandro Mutschall e Cols. so tem sido demonstrado como um fator de grande relevância, uma vez que o desenvolvimento de novos vasos sangüíneos são necessários para o suporte de oxigênio, de nutrientes, e também para remover moléculas tóxicas ${ }^{3}$. A indução da angiogênese é regulada por várias moléculas que podem ser liberadas por células tumorais, ou células normais, incluindo células endoteliais, células epiteliais, células mesoteliais e leucócitos. Dentre estas moléculas esta um grupo de proteínas chamadas de VEGF (vascular endothelial growth factor), sendo considerado um dos mais importantes fatores de crescimento endotelial e indutor da angiogênese ${ }^{4}$. Esta proteína, provavelmente está ligada ao crescimento tumoral e ao aparecimento de metástases. Sendo assim, supomos que a expressão da proteína VEGF, nos carcinomas colorretais possa apresentar-se de forma diretamente proporcional ao grau de estadiamento tumoral, representado em especial pela presença de metástases linfonodais.

A imunoistoquímica tem sido empregada como técnica padrão para a identificação da expressão e quantificação tecidual de proteínas, sendo hoje uma ferramenta básica nos estudos de biologia molecular. Utilizada usualmente na prática clínica através da análise de espécimes individuais em lâminas, estudos realizados ao longo dos últimos anos tem a associado com a técnica Matriz de Amostras Teciduais (Tissue Array), através da qual podemos agregar múltiplas amostras de diferentes tecidos em uma mesma lâmina. A quantificação imunoistoquímica normalmente é realizada por observadores (semiquantitativa), porém a quantificação via análise de imagens assistida por computador vem se tornando popular no meio científico.

O objetivo do presente estudo é verificar a hipótese de que os níveis de expressão imunoistoquímica da proteína VEGF nos carcinomas colorretais são maiores nos tumores com presença de metástase em linfonodos regionais, utilizando-se uma Matriz de Amostras Teciduais e análise de imagens assistida por computador.

\section{MÉTODOS}

\section{Casuística}

Trata-se de um estudo retrospectivo onde foram selecionados espécimes resultantes de 56 ressecções cirúrgicas colorretais com diagnóstico de adenocarcinoma. Essas amostras encontravam-se arquivadas em blocos de parafina, disponíveis no Labo- ratório de Anatomia Patológica SIP, localizado na cidade de Joinville, Santa Catarina. As amostras foram numeradas e os nomes dos pacientes não foram utilizados, mantendo-se o sigilo. Esta amostragem foi subdividida em dois grupos, a saber: grupo A adenocarcinomas colorretais classificados como Estádio I e II pela classificação TNM, ou seja, aqueles nos quais não foi identificada a presença de invasão neoplásica em linfonodos; grupo B - adenocarcinomas colorretais classificados como Estádio III, ou seja, aquelas nos quais foi identificada a presença de no mínimo um linfonodo comprometido pelo tecido neoplásico. Foram incluídas apenas as amostras que possuíam presença de estadiamento tumoral completo pela classificação TNM e cujos blocos de parafina contendo tecido tumoral mostraram-se adequados à realização do presente estudo.

\section{Construção da Matriz de Amostras Teciduais (Tissue Array) \\ Após a seleção dos casos, foram escolhidos} os blocos de parafina mais representativos do espécime tumoral baseado na análise de sua lâmina correspondente corada com Hematoxilina e Eosina (HE). Foi feita uma revisão microscópica desta para identificação dos segmentos com tecido tumoral, nos quais foi extraída uma amostra do bloco de parafina correspondente com a utilização de um "punch" descartável para biópsia de pele, com $5 \mathrm{~mm}$ de diâmetro. Multiblocos destes fragmentos de amostras foram montados, sempre registrando a posição de cada um para posterior identificação (Figura 1).
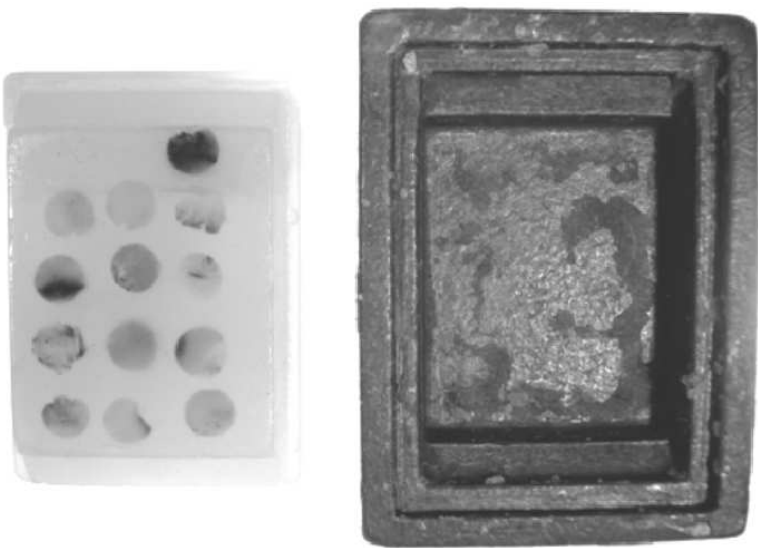

Figura 1 - Multibloco e seu respectivo molde. O tecido no canto superior direito foi colocado como marcador da primeira amostra da matriz e não pertence às amostras do estudo. 
Análise da Relação entre a Expressão da Proteína VEGF

e o Estadiamento do Câncer Colorretal

Leandro Mutschall e Cols.
Vol. 29

\section{Imunoistoquímica}

De cada multibloco foi realizado um corte histológico o qual foi fixado em lâmina a qual, após tratamento, foi incubada com o anticorpo monoclonal para detecção da proteína VEGF humana (affinity BioReagents, $n^{\circ}$ MA1-16629). A detecção do anticorpo primário foi realizada com o sistema $\mathrm{LSAB}^{\mathrm{TM}}+$ SystemHRP do fabricante Dako (código K0690), e a visualização foi obtida com o kit DAB+ Substrate Cromogen System do fabricante Dako (código K3468). A quantificação da reação imunoistoquímica foi realizada através da analise das microfotografias das amostras, auxiliada pelo software Image Pro-Plus 6.0 (Media Cybernetics, USA).

\section{Análise Digital da Imagem}

Usando-se idênticas configurações de microscopia e fotografia, foram obtidas três imagens de cada amostra estudada (Figura 2) com uma objetiva de 40 vezes em microscópio Nikon, modelo Eclipse E200. As imagens foram auto balanceadas através do software Microsoft PhotoEditor para melhora do contraste e do brilho. Após análise visual do conjunto, as imagens foram processadas utilizando-se uma escala padronizada de cores incluindo amplitudes respectivas para o vermelho (87-203), verde (15-165) e azul (0-121).

As três imagens de cada amostra foram submetidas a este processo, tendo a determinação do nível (escore) de expressão da proteína VEGF sido obtida pela multiplicação da densidade média pelo percentual das áreas positivamente coradas pela imunoistoquímica (áreas de coloração marrom). A obtenção do escore final de expressão da proteína VEGF para cada amostra foi obtida através da média aritmética entre o resultado individual de cada uma das três imagens da amostra.

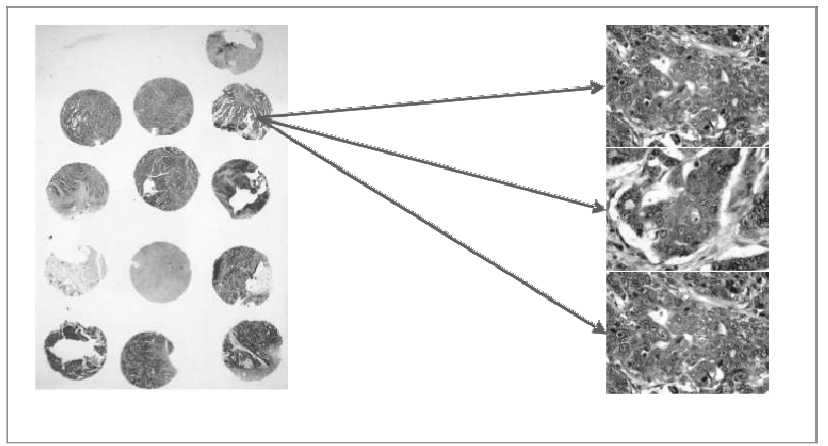

Figura 2 - Lâmina de multibloco submetida à detecção da proteína VEGF juntamente com as três imagens obtidas de uma das amostras.

\section{Análise Estatística}

O software Epi Info ${ }^{\mathrm{TM}}$ versão 3.5.1 foi utilizado para efetuar as análises estatísticas deste trabalho. As comparações foram efetuadas com o teste ANOVA ou com o teste Mann-Whitney/Kruskal-Wallis quando as variáveis não estavam normalmente distribuídas. As variáveis categóricas foram analisadas usando-se o teste ${ }^{2}$ ou o exato de Fisher.

O projeto deste trabalho foi analisado pelo do Comitê de Ética em Pesquisa da Universidade de Região de Joinville - UNIVILLE, e teve sua execução aprovada pelo ofício $n^{\circ} 103 / 2007$ por atender plenamente aos parâmetros descritos na Resolução 196/96 do Conselho Nacional de Saúde.

\section{RESULTADOS}

Cinquenta e seis pacientes foram incluídos neste estudo, 28 pertencentes ao grupo A (sem metástase em linfonodos) e 28 pertencentes ao grupo B (com metástase em linfonodos). A distribuição por sexo, idade e estadiamento dos dois grupos estão representados na Tabela 1.

Tabela 1 - Dados pessoais e histopatológicos dos dois grupos de pacientes estudados. Grupo A (linfonodos negativos) e grupo $B$ (linfonodos positivos).

\begin{tabular}{lccc}
\hline & Grupo A & Grupo B & Valor de p \\
\hline Sexo & & & \\
Masculino & 16 & 13 & $\mathrm{p}=0,42$ \\
Feminino & 12 & 15 & \\
Idade Média & & & \\
& 63,2 & 60,5 & $\mathrm{p}=0,48$ \\
Estadiamento & & & \\
I & 7 & & \\
IIA & 20 & & \\
IIB & 1 & & \\
IIIA & & 2 & \\
IIIB & & 16 & \\
IIIC & & 10 & \\
Profundidade do Tumor & & \\
pT2 & 7 & 1 & \\
pT3 & 20 & 23 & \\
pT4 & 1 & 4 & \\
Linfonodos & Comprometidos & \\
pN0 & 28 & - & \\
pN1 & & 17 & \\
pN2 & & 11 & \\
\hline
\end{tabular}


Análise da Relação entre a Expressão da Proteína VEGF

e o Estadiamento do Câncer Colorretal

Leandro Mutschall e Cols.
Vol. 29
Os escores obtidos na avaliação da expressão da proteína VEGF das 56 amostras deste estudo variaram de 2,15 até 48,36 (Figura 3).

No grupo A o menor valor de escore foi de 2,15 e o maior 42,83 , com uma média de 24,49 e um desvio-padrão de 10,91. No grupo B o menor valor de escore foi de 7,86 e o maior 48,36, com uma média de 24,42 e desvio-padrão de 9,88 . As variações entre os escores obtidos nos grupos A e B não foram estatisticamente significativas $(\mathrm{p}=0,98)$, e os valores de cada caso podem ser observados na tabela 2 .

Conforme o estadiamento tumoral, o menor escore pertenceu ao estádio I e o maior ao estádio IIIC. Apenas uma amostra foi classificada como estádio IIB com um escore de 34,40. O estádio IIIA foi representado por duas amostras, com uma média de 19,65. Como pode ser observado na tabela 3 entre as amostras restantes, a menor média de escore pertence aos casos classificados como estádio I $(23,16)$. A maior média de escore pertence aos casos classificados como estádio IIIC $(26,63)$. Aparentemente há uma diferença entre média do escore de expressão das amostras classificadas como estádio I e estádio IIIC, entretanto estatisticamente essas diferenças não foram significativas $(p=0,84)$.
Conforme a profundidade de invasão tumoral, a menor média do escore de expressão da proteína VEGF foi de 22,92 e desvio-padrão de 7,06 pertencente aos tumores classificados como pT4. A maior média de escore foi 24,87 com desvio-padrão de 10,75 obtida dos tumores classificados como pT3. O grupo de amostras classificadas como pT2 teve uma média de 23,16 e um desvio-padrão de 10,44. Como pode ser observado na tabela 4 as diferenças observadas nas médias dos grupos separados pela profundidade de invasão tumoral não foram estatisticamente relevantes $(\mathrm{p}=0,86)$.

Divididas as amostras conforme o número de linfonodos comprometidos (tabela 5), o grupo classificado como pN1 (1 a 3 linfonodos comprometidos) exibiu a menor média de expressão da proteína VEGF, ficando em 23,61 com desvio-padrão de 9,59. A maior média foi do grupo classificado como pN2 (4 ou mais linfonodos comprometidos) 25,67 e desvio-padrão de 10,67. O grupo pN0 (sem linfonodos comprometidos) ficou com uma média intermediária de 24,49 e desvio-padrão de 10,91 . As diferenças observadas não são relevantes estatisticamente $(\mathrm{p}=0,87)$.
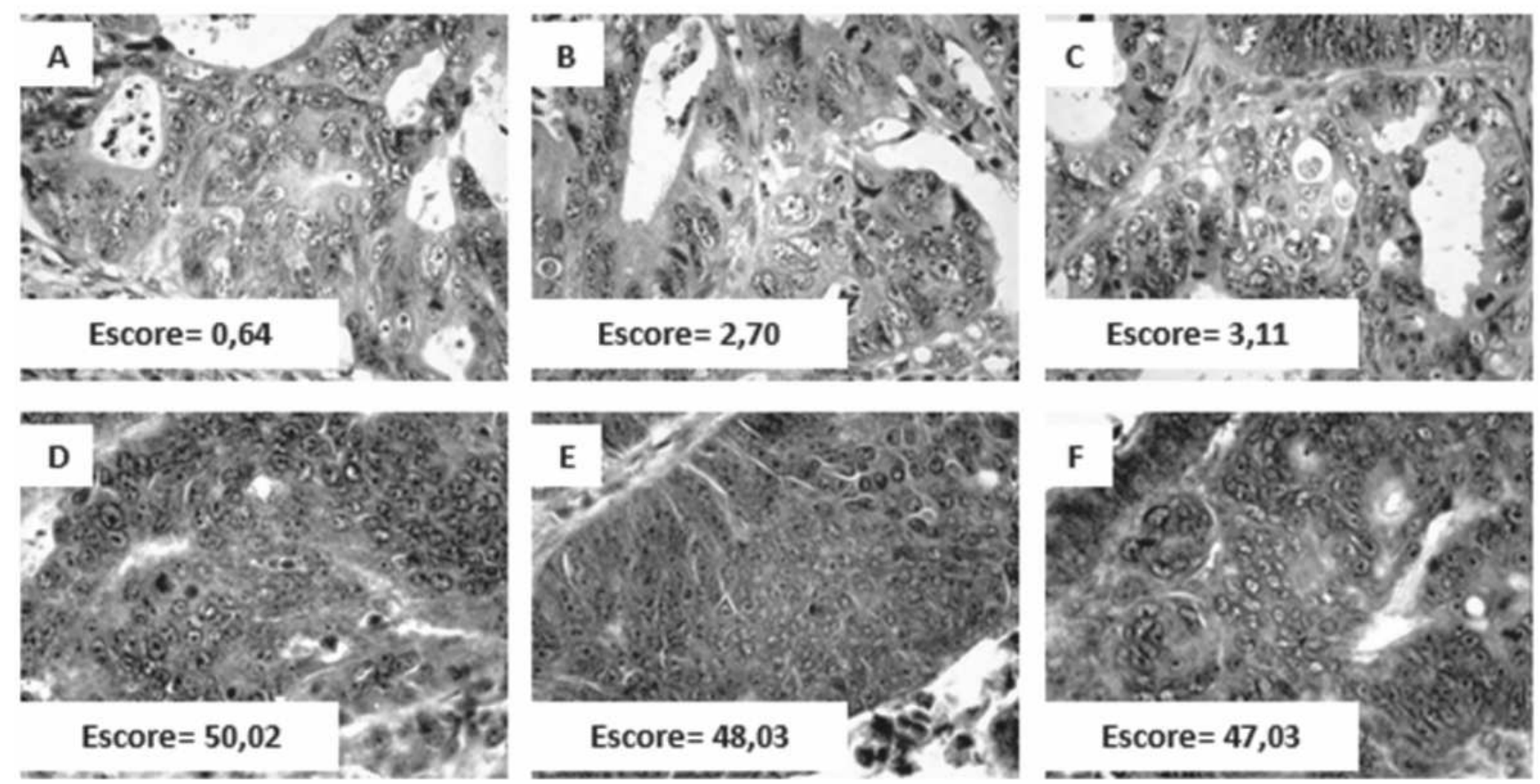

Figura 3 - Imagens para detecção da proteína VEGF.

Fotos A a C: caso $n^{\circ} 1$, escore médio de 2,15. Fotos D a F: caso $n^{\circ} 56$, escore médio 48,36. 
Tabela 2 - Valores do escore de expressão da proteína VEGF em ordem crescente e separados por grupo.

\begin{tabular}{|c|c|c|c|}
\hline \multicolumn{2}{|c|}{ Grupo A $n=28$} & \multicolumn{2}{|c|}{ Grupo B $n=28$} \\
\hline$N^{o}$ do exame & Escore médio & $\mathbf{N}^{0}$ do exame & Escore médio \\
\hline 1 & 2,15 & 29 & 7,86 \\
\hline 2 & 4,33 & 30 & 10,38 \\
\hline 3 & 10,80 & 31 & 13,93 \\
\hline 4 & 11,74 & 32 & 14,60 \\
\hline 5 & 11,98 & 33 & 14,73 \\
\hline 6 & 13,33 & 34 & 16,07 \\
\hline 7 & 18,12 & 35 & 17,42 \\
\hline 8 & 18,61 & 36 & 17,51 \\
\hline 9 & 19,08 & 37 & 18,20 \\
\hline 10 & 20,73 & 38 & 18,28 \\
\hline 11 & 21,84 & 39 & 20,21 \\
\hline 12 & 22,01 & 40 & 20,45 \\
\hline 13 & 23,26 & 41 & 20,64 \\
\hline 14 & 24,05 & 42 & 20,71 \\
\hline 15 & 24,95 & 43 & 23,23 \\
\hline 16 & 26,40 & 44 & 24,66 \\
\hline 17 & 26,93 & 45 & 25,07 \\
\hline 18 & 27,47 & 46 & 26,98 \\
\hline 19 & 28,63 & 47 & 28,54 \\
\hline 20 & 28,99 & 48 & 29,11 \\
\hline 21 & 30,64 & 49 & 29,85 \\
\hline 22 & 33,78 & 50 & 31,62 \\
\hline 23 & 34,40 & 51 & 34,46 \\
\hline 24 & 36,96 & 52 & 35,19 \\
\hline 25 & 39,90 & 53 & 35,54 \\
\hline 26 & 40,08 & 54 & 35,97 \\
\hline 27 & 41,63 & 55 & 44,10 \\
\hline 28 & 42,83 & 56 & 48,36 \\
\hline Média & 24,49 & Média & 24,42 \\
\hline Desvio-padrão & 10,91 & Desvio-padrão & 9,88 \\
\hline
\end{tabular}

$\mathbf{p}=\mathbf{0 , 9 8}$

\section{DISCUSSÃO}

Os resultados obtidos no presente estudo representam uma informação adicional dentro do amplo espectro de achados que buscaram relacionar a expressão da proteína VEGF e as diferentes variáveis no câncer colorretal como estadiamento, grau histológico, tamanho do tumor, metástases linfonodais ou à distância e prognóstico.

A ausência de correlação significativa aqui observada entre a expressão tumoral de VEGF, a pre- sença de invasão linfonodal e o estadiamento corrobora outros estudos já efetuados os quais, embora utilizando metodologias distintas e analisando algumas outras variáveis, também encontraram resultados que não confirmaram a possível relação entre a expressão da proteína VEGF e outros fatores prognósticos padronizados, atualmente utilizados em pacientes portadores de câncer colorretal ${ }^{5,6,7}$.

Por outro lado, a controvérsia a este respeito reside na existência de outros estudos os quais lograram evidenciar diferenças significativas relativas à ex- 
Tabela 3 - Dados estatísticos obtidos na comparação dos escores com o estadiamento tumoral.

\begin{tabular}{lrccccc}
\hline Estadiamento & N & Menor escore & Maior escore & Média & Desvio-padrão & Valor de p \\
\hline I & 7 & 2,15 & 40,08 & 23,16 & 11,28 & 0,84 \\
IIA & 20 & 4,33 & 42,83 & 24,46 & 11,09 & \\
IIB & 1 & 34,40 & 34,40 & 34,40 & - & \\
IIIA & 2 & 16,07 & 23,23 & 19,65 & 5,06 & \\
IIIB & 16 & 7,86 & 44,10 & 23,63 & 9,90 & \\
IIIC & 10 & 13,93 & 48,36 & 26,63 & 10,74 & \\
\hline
\end{tabular}

Tabela 4 - Comparação da expressão da proteína VEGF com a profundidade de invasão tumoral.

\begin{tabular}{ccccc}
\hline Profundidade do tumor & $\mathbf{n = ~ 5 6}$ & Média & Desvio-padrão & Valor de p \\
\hline pT2 & 8 & 23,16 & 10,44 & 0,86 \\
pT3 & 43 & 24,87 & 10,75 & \\
pT4 & 5 & 22,92 & 7,06 & \\
\hline
\end{tabular}

Tabela 5 - Comparação da expressão da proteína VEGF com o número de linfonodos invadidos.

\begin{tabular}{ccccc}
\hline Linfonodos Invadidos & $\mathbf{n = 5 6}$ & Média & Desvio-padrão & Valor de $\mathbf{p}$ \\
\hline pN0 & 28 & 24,49 & 10,91 & 0,87 \\
pN1 & 17 & 23,61 & 9,59 & \\
pN2 & 11 & 25,67 & 10,67 & \\
\hline
\end{tabular}

pressão desta proteína. Funaki et $a l^{8}$, embora não tenham observado relação significativa com diversas variáveis tumorais, demonstrou uma diferença significativa de expressão no que diz respeito à presença de metástases linfonodais. Resultados semelhantes foram encontrados por Kazama et al ${ }^{9}$, os quais também encontraram diferença significativa em relação à metástases linfonodais, invasão linfática e o tamanho do tumor. No estudo realizado por Takahashi et al ${ }^{10}$ a intensidade da reação para detecção da proteína VEGF foi significativamente maior nos tumores com metástase do que nos tumores sem metástase e adenomas ( $\mathrm{p}<0,001$ e p $<0,001$ respectivamente), embora não tenha ocorrido esta diferença entre a intensidade de coloração dos tumores sem metástase e os adenomas. Cascinu et al ${ }^{11}$ após estudarem a expressão da proteína VEGF em 121 pacientes com carcinoma colorretal, todos classificados em estádio II, comprovaram a idéia de que a proteína VEGF pode ser utilizada para identificar pacientes com alto risco de recorrência tumoral, e que estes poderiam beneficiar-se de um tratamento adjuvante.

A inexistência de consenso a respeito da correlação dos níveis de expressão da proteína VEGF com outros fatores prognósticos contrasta com sua crescente importância clínica. A expressão da proteína VEGF em vários tumores humanos geralmente está correlacionada com a progressão tumoral e mau prognóstico ruim, motivo pelo qual tornou-se um alvo para o desenvolvimento de agentes terapêuticos ${ }^{12}$.

Nos anos 90 foi desenvolvido um anticorpo monoclonal contra a proteína VEGF-A, denominado como bevacizumab, o qual vem sendo utilizado com resultados bastante promissores ${ }^{13}$. Alguns estudos já demonstraram que a adição de bevacizumab à quimioterapia tradicional mostrou 
Análise da Relação entre a Expressão da Proteína VEGF

e o Estadiamento do Câncer Colorretal

Leandro Mutschall e Cols. aumento da sobrevida dos pacientes com aceitável toxicidade. O FDA (Food and Drug Administration) dos Estados Unidos aprovou a utilização do bevacizumab em pacientes com tumores de cólon irressecáveis e tumores de pulmão não escamoso, não de pequenas células, também irressecáveis. Em abril de 2007 o Ministro Japonês da Saúde, Trabalho e Bem Estar Social aprovou o uso de bevacizumab para tratamento de pacientes com tumores de cólon irressecáveis ${ }^{14}$.

Weihrauch et al ${ }^{15}$ relataram o caso de um paciente com 62 anos de idade, que teve diagnosticado no ano de 2001 um adenocarcinoma de cólon estádio III. No ano de 2008 apresentou uma grande metástase hepática, irressecável e com linfonodos do hilo hepático envolvidos. Após o tratamento adjuvante com cetuximab, bevacizumab e XELOX (Capecitabine Plus Oxaliplatin) o paciente mostrou completa remissão tumoral. Foi então realizada cirurgia para remoção dos resíduos teciduais que ao serem submetidos ao exame histopatológico não evidenciaram tumor residual.

RNA de inteferência (RNAi) é uma tecnologia emergente e potente, capaz de reduzir a expressão de genes desejados. Estudos recentes tem utilizado esta tecnologia para controlar a expressão da proteína VEGF em diversos modelos tumorais. A utilização do RNAi não está em fase tão avançada como o bevacizumab, porém resultados recentes mostram que esta tecnologia é bastante eficiente no controle da expressão gênica.

Mulkeen et al ${ }^{16}$ testaram a capacidade do RNAi para reduzir a expressão da proteína VEGF em células de câncer de cólon. As células transfectadas com o RNAi mostraram um decréscimo de $94 \%$ da expressão da proteína VEGF, e 67\% de decréscimo na proliferação celular. Outro estudo realizado na China por He et al ${ }^{17}$ utilizou RNAi para controlar a expressão da proteína VEGF in vivo e in vitro. A expressão do RNA mensageiro para a proteína VEGF-C e da proteína VEGF-C in vitro foi significativamente reduzida $(45,3 \%$ e $35,3 \%$ respectivamente). In vivo, quatro semanas após a injeção do RNAi o volume tumoral foi significativamente menor, bem como a incidência de metástase em linfonodos $(30 \%)$.
Outro aspecto a ser discutido referente ao trabalho aqui apresentado diz respeito à aplicabilidade dos recursos utilizados para análise dos testes de imunoistoquímica, os quais incluíram a elaboração de uma matriz de amostras teciduais e a leitura dos resultados utilizando a análise de imagens assistida por computador.

Nossa experiência com a construção de uma matriz de amostras teciduais para a análise conjunta retrospectiva de uma série de casos através de imunoistoquímica confirmou os relatos favoráveis encontrados na literatura. Além de tecnicamente simples e viável, sua utilização implicou em diversos benefícios entre os quais poderíamos citar em especial a possibilidade de um maior controle de variações na coloração relacionadas à necessidade de vários procedimentos (baterias), uma vez que todas as lâminas podem ser coradas através de um único procedimento, o que implica ainda, por seu turno em uma redução do custo devido à necessidade de menores volumes de reagentes, incluindo anticorpos monoclonais.

No que diz respeito à utilização de análise digital de imagens, trata-se de uma questão mais complexa de ser avaliada. Considerando-se que o procedimento padrão para quantificação da coloração restringia-se à avaliação puramente subjetiva visual, inexiste uma referência estritamente objetiva capaz de determinar a eficiência e confiabilidade dos métodos de medida digital amplamente utilizados ao longo dos últimos anos. Esta dificuldade é ainda agravada pelo fato de que estes últimos também incluem um importante componente subjetivo como a determinação de campos e a definição do espectro colorimétrico a ser empregado. Mesmo considerando estas ressalvas, nossa experiência com a análise digital neste trabalho mostrou-se aparentemente confiável e coerente, confirmando os relatos favoráveis de outros estudos que utilizaram este recurso ${ }^{18,19,20 .}$

Assim sendo, concluímos não ser possível confirmar a partir deste estudo a hipótese de que os níveis de expressão imunoistoquímica da proteína VEGF nos carcinomas colorretais são maiores nos tumores com presença de metástase em linfonodos regionais, utilizando-se uma Matriz de Amostras Teciduais e análise de imagens assistida por computador. 
Rev bras Coloproct

Janeiro/Março, 2009
Análise da Relação entre a Expressão da Proteína VEGF

$\boldsymbol{e}$ o Estadiamento do Câncer Colorretal

Leandro Mutschall e Cols.
Vol. 29

\begin{abstract}
Development of studies in molecular biology over the last decades has contributed for better knowledge about colorectal carcinogenesis. An important landmark in this process was the identification of a protein with effect on vascular permeability eventually named as vascular endothelial growth factor (VEGF), which seems to be essential for the angiogenesis activation of tumor development. The aim of this study was to assess the VEGF expression and correlate to tumor staging in colorectal cancer. Surgical specimens from 56 colorectal cancer patients were analyzed by immunohistochemistry for VEGF expression using a multitissue array and a computer-assisted image system. No significant result was found between VEGF expression and tumor staging or lymph nodes metastasis. We concluded that no predictive value for lymph nodes metastasis could be demonstrated by VEGF immunostaining in this study.
\end{abstract}

Key words: Colorectal cancer; molecular biology; VEGF; staging; immunohistochemstry.

\section{REFERÊNCIAS}

1. Fearon, E. R.; Vogelstein, B. A genetic model for colorectal tumorigenesis. Cell 1990;61:759-767.

2. Vogelstein, B. et al. Genetic alterations during colorectal-tumor development. The New England Journal of Medicine 1988;319(9):525-532.

3. Folkman, J. Tumor Angiongenesis: Therapeutic implications. N Engl J Med 1971;285:1182-1186.

4. Ferrara, N.; Gerber, H.; Le-Couter, J. The biology of VEGF and its receptors. Nature Medicine 2003; 9(6):669-676,

5. AltomarE, D. F. et al. Tissue factor and vascular endothelial growth factor expression in colorectal cancer: relation with cancer recurrence. Colorectal Dis 2007; 9(2):133-138.

6. Kekec, Y. et al. Prognostic significance of vascular endothelial growth factor-A Expression in colorectal cancer. J. Cancer Mol 2006; 2(4):161-167.

7. Zheng, S. et al. Clinical significance of vascular endothelial growth factor expression and neovascularization in colorectal carcinoma. World J Gastroenterol 2003; 9(6):1227-1230.

8. Funaki, H. et al. Expression of vascular endothelial growth factor-D is associated with lymph node metastasis in human colorectal carcinoma. Oncology 2003; 64:416-422.

9. Kazama, S. et al. Expression pattern of vascular endothelial growth factor in human colorectal normal mucosa and neoplastic mucosa. Hepatogastroenterology 2004; 51(56):391:395.

10. Takahashi, Y. et al. Expression of vascular endothelial growth factor and Its receptor, KDR, correlates with vascularity, metastasis, and proliferation of human colon cancer. Cancer Research 1995; 55(15):3964-3968.

11. Cascinu, S. et al. Expression of vascular endothelial growth factor can predict event-free survival in stage II colon cancer. Clinical Cancer Research 2000; 6:2803-2807.
12. Diaz-rubio, E. Vascular endothelial growth factor inhibitors in colon cancer. Adv Exp Med Biol 2006; 587:251-275,.

13. Ferrara, N. et al. Discovery and development of bevacizumab, an anti VEGF antibody for treating cancer. Nature Ver Cancer 2004; 3:391-400.

14. Yamazaki K, Yoshino T, Boku N. Bevacizumab (Avastin). Gan To Kagaku Ryoho 2007; 34(8):1183-1191.

15. Weihrauch, M. R. et al. Complete remission in a colon cancer patient with a large, irresectable liver metastasis after XELOX/cetuximab/ bevacizumar treatment. Onkologie 2008; 31(8-9):464-467.

16. Mulkeen, a. L. et al. Short interfering RNA-mediated gene silencing of vascular endothelial growth factor: effects on cellular proliferation in colon cancer cells. Arch Surg 2006; 141(4)367-374.

17. He, X. W. et al. Vector-based RNA interference against vascular endothelial growth factor-C inhibits tumor limphangiogenesis and growth of colorectal cancer in vivo in mice. Chin Med J (Engl) 2008; 121(5):439-444.

18. Carai, A. et al. Computerized quantitative color analysis for histological study of pulmonary fibrosis. Anticancer Res 2002; 22(6C):3889-3894.

19. Diaz, L. K. et al. Interobserver agreement for estrogen receptor immunohistochemical analysis um breast cancer: a comparison of manual and computer-assisted scoring methods. Ann Diagn Pathol 2004; 8(1):23-27.

20. Rieux, C. et al. Analysis of immunohistochemical label of FOS protein in the suprachiasmatic nucleus: comparison of differents methods of quantification. J Biol Rhythms 2002; 17(2):121-136.

Endereço para correspondência:

MAURO PINHO

Rua Palmares 380 - Joinville - 89203-230

mauro.pinho@terra.com.br

Fax: (47) 3422-6565 